\title{
Cuidados Parentais e Aloparentais Recebidos por Crianças de Escolas Públicas e Particulares de Vitória - ES
}

\author{
Parental and Aloparental Care Received by Children in Public \\ and Private Schools in Vitória, ES
}

\author{
Lara Wright Silva \& Rosana Tokumaru* \\ Universidade Federal do Espírito Santo, Vitória, Brasil
}

\begin{abstract}
Resumo
Investigamos a participação dos pais e de outros adultos no fornecimento de cuidados às crianças em dois contextos socioeconômicos. Encontramos predominância dos pais como cuidadores e participação de alocuidadores aparentados e não aparentados em todos os cuidados mensurados. Houve diferença em função dos contextos. Pais e mães de crianças matriculadas em escolas públicas compartilharam mais as tarefas de cuidado que os de crianças em escolas particulares. Os alocuidadores mais frequientes das crianças de escolas públicas foram os parentes, enquanto os empregados prevaleceram como alocuidadores de crianças de escolas particulares. Nossos resultados indicam que os contextos socioeconômicos são fatores importantes de variação no fornecimento de cuidados às crianças, tanto por parte dos pais como por parte de outros cuidadores.

Palavras-chave: Cuidado parental; cuidado aloparental; contexto socioeconômico.
\end{abstract}

\begin{abstract}
We investigated the participation of parents and other adults in the caretaking of children in two socioeconomic contexts. We found the caretaking is predominant whith participation of related and non that parental related aloparents in all the caretaking tasks assessed. There were differences due to the contexts. Parents of children attending public schools shared more caretaking tasks than parents of children attending private schools. Related aloparents were more frequently responsible for the caretaking of children from public schools while employees were more frequently responsible for children from private schools. Our results show that the socio-economic context is an important factor in the variation of caretaking of children, both for parents and aloparents.

Keywords: Parental care; aloparental care; socio-economic context
\end{abstract}

A grande dependência da criança dos adultos que a cercam é uma característica do desenvolvimento humano diretamente relacionada à nossa história evolutiva, que envolveu uma socialização extensiva (Bussab \& Ribeiro, 1998; I. M. M. Carvalho \& Almeida, 2003; Rodrigues, 1998). Neste contexto, o cuidado parental pode ter tido como principal função prover um meio para o desenvolvimento das competências sócio-cognitivas da criança de forma a torná-la um competidor habilidoso na comunidade na qual se insere (Geary \& Flinn, 2001). O alto custo do lento desenvolvimento infantil pode ter levado à evolução de um sistema cooperativo de reprodução humana (Hrdy, 2006) que envolve principalmente os parentes como alocuidadores. O benefício para o alocuidador aparentado é representado pelo aumento em sua aptidão abrangente. Benefícios indiretos podem ser obtidos, como treino em maternidade (Roulin, 2002). Nas espécies com cuidado cooperativo, como por exemplo, calitriquídeos (Yamamoto

\footnotetext{
*Endereço para correspondência: Universidade Federal do Espírito Santo, Departamento de Psicologia Social e do Desenvolvimento, Av. Fernando Ferrari, s/n., Goiabeiras, Vitória, ES, 29060-900. E-mail: tokumaru@usp.br
}

\& Souza, 1998), têm-se encontrado correlação positiva entre a sobrevivência dos filhotes e o número de ajudantes no grupo. No caso humano, tem-se observado que mães sem suporte social tendem a abandonar mais seus bebês que mães com suporte social (ver Hrdy, 2001). O suporte social pode ser visto como a presença de alocuidadores (Hrdy, 2006; Key \& Aiello, 1999).

Supõe-se que um padrão humano na prática de criação de crianças seja a ampliação das redes sociais da criança a partir de uma ou mais relações iniciais (principalmente parentes próximos) para unidades sociais maiores e mais complexas (A. M. A. Carvalho, 1998). No entanto, este padrão pode ser afetado por diversas condições. Por exemplo, Rapoport e Piccinini (2004) indicam que a migração de pessoas do interior para os grandes centros urbanos, a diminuição do tamanho das famílias e a busca pela individualidade tem afetado as relações da família com a rede de apoio familiar e com a vizinhança provocando novas formas de cuidado de bebês e crianças pequenas como o uso de creche ou de empregada/babá. Os autores caracterizam este cuidado como alternativo e demonstram que há relação entre determinadas características maternas como condições socioeconômicas, idade e condições de trabalho 
e a escolha do tipo de cuidado al ternativo. Österberg (2000) demonstrou, na Suécia, que a menor disponibilidade de recursos econômicos e o expediente irregular dos pais relacionam-se ao maior nível de necessidades não atendidas das crianças e que os adultos mais acessíveis durante o expediente dos pais, para metade das crianças pré-escolares, são os membros da equipe da creche.

Amazonas, Damasceno, Terto e Silva (2003) apontaram que famílias de classes populares do Recife (PE) não apresentaram uma delimitação clara no exercício das funções de provedor e de fornecimento de cuidados e afetos e que os filhos freqüentemente representaram, para estas famílias, maior força de trabalho e ganhos econômicos e não apenas despesas.

As condições socioeconômicas podem ser importantes também para as atitudes maternas. Oliveira, Frizzo e Marin (2000) relataram que a chance de desenvolver atitudes maternas psicopatogênicas (intrusão, irritabilidade) cresceu linearmente na medida que o nível socioeconômico da mãe decresceu. Silva, Pendu e Pontes (2002) sugeriram que mães de classe baixa que tinham pouca escolaridade apresentavam menos comportamentos indicadores de sensibilidade materna e mais comportamentos negativos que mães da classe média. Mostraram ainda que as mães que dividiam a tarefa de cuidar da criança com outras pessoas emitiram com mais freqüência comportamentos positivos que mães que executavam estas tarefas sozinhas. Lordelo, Fonseca e Araujo (2000) observaram que os níveis de responsividade materna foram muito mais altos entre as mães de classe média e escolaridade superior. Braz, Dessen e Silva (2005) encontraram que os pais de classe média consideram mais importante transmitir aos filhos valores relativos à sociabilidade e à afetividade, enquanto a classe baixa enfatiza a educação formal, o respeito e os valores morais. As classes sociais média e baixa foram definidas a partir do nível de escolaridade e ocupação dos genitores, renda familiar e local de moradia da família.

Os trabalhos apresentados mostram que a classe socioeconômica dos cuidadores, principalmente mães e pais, tem grande influência sobre suas práticas de criação, sobre os valores e crenças que possuem a respeito da criação de filhos e sobre a sensibilidade materna. Poucos trabalhos têm investigado a participação dos alocuidadores no fornecimento de cuidados, apesar de apontarem a importância que têm adquirido modernamente. Tanto o cuidado alternativo, dado por membros da equipe de creches e escolas e por empregados (Österberg, 2000; Rapoport \& Piccinini, 2004), quanto a participação de parentes como alocuidadores (Silva et al., 2002) parecem variar em função da classe socioeconômica dos pais.

Pretendemos investigar como diferentes cuidadores: pais e alocuidadores, participam no fornecimento de cuidados às crianças de $\mathrm{O}$ a 6 anos matriculadas em escolas públicas e particulares da cidade de Vitória-ES, Brasil. Esta faixa etária foi escolhida dada a maior dependência de cuidado que estas crianças requerem (Wagner, Predebon, Mosmann \& Verza, 2005). Estudos em diferentes municípios brasileiros têm demonstrado que alunos matriculados em es- colas públicas apresentam nível socioeconômico mais baixo que alunos matriculados em escolas particulares (La Rosa, 1998; Leão, Araújo, Moraes \& Assis, 2003; Machado, Marcari, Cristante \& Carareto, 1999; Martins et al., 2006; Pinho, 2001; Pires \& Lopes, 2004). Consideramos, portanto, que as escolas públicas e particulares investigadas na presente pesquisa reflitam realidades socioeconômicas diferentes. Não encontramos referência à classe socioeconômica dos usuários de escolas públicas e particulares em censos oficiais do Instituto Nacional de Estudos e Pesquisas Educacionais ([INEP], 2006) e Instituto Brasileiro de Geografia e Estatística ([IBGE], 2006) divulgado nos sítios oficiais destes órgãos.

\section{Método}

\section{Sujeitos}

Participaram da pesquisa os responsáveis por crianças com idade entre o e 6 anos matriculadas em dezessete escolas do município de Vitória, ES, nove públicas e oito particulares. A forma de recrutamento dos participantes está descrita nos procedimentos e suas características encontram-se nos resultados.

\section{Instrumento}

O instrumento de coleta foi um questionário contendo perguntas fechadas de múltipla escolha. As questões se referiam: (a) ao perfil da criança que levou o questionário para casa (idade, sexo, coabitação, se a criança tinha irmãos e quantos, se era aluno bolsista); (b) ao perfil da pessoa que respondia o questionário (escolaridade, o que era da criança, se trabalhava fora e com quem ficava a criança no período de trabalho dos pais); (c) aos cuidados dados à criança por toda a família (quem levava à escola, o principal (ou principais) responsável(responsáveis) pelos gastos, alimentação e higiene); (d) à freqüência ("não realiza", "poucas vezes", “às vezes”, "muitas vezes”) com que o respondente realizava as seguintes tarefas com a criança: brincar, levar para passear, dar presentes, conversar, levar à escola, auxiliar nas tarefas escolares, levar ao médico, cuidar da alimentação, cuidar da higiene e corrigir as atitudes inadequadas das crianças; (e) a gravidade, em uma escala de 1 (nada grave) a 5 (extremamente grave), que o respondente atribuía as seguintes atitudes inadequadas das crianças: teimosia, uso de palavrões, desobediência, mentira, falta de respeito, gritos, falta de educação, falta de higiene, irresponsabilidade com os estudos, brincadeiras perigosas, reclamações da escola.

\section{Procedimento de Coleta de Dados}

As instituições de ensino nos quais os questionários foram distribuídos foram sorteadas (método de amostragem aleatória) a partir da lista obtida no INEP, do ano de 2004 contendo todas as escolas do município de Vitória, ES. O número de questionários entregue a cada criança variou de acordo com a orientação dos pedagogos sobre a constituição familiar, tendo sido entregues de um a sete questionários para cada criança. Os questionários eram coloca- 
dos nas agendas escolares das crianças juntamente com um bilhete aos cuidadores pedindo que cada um respondesse a um questionário e os devolvessem à escola. O número total de questionários respondidos obtidos foi de 503 dos 2000 questionários enviados.

\section{Análise dos Dados}

Dos questionários respondidos pelos participantes, selecionamos aleatoriamente, por meio de sorteio, um questionário respondido para cada criança. Comparamos os sujeitos responsáveis pelas crianças matriculadas nas escolas públicas e particulares, usando o teste de $\chi^{2}$, quanto à classe de cuidador que respondeu o questionário, à escolaridade do respondente, à freqüência de pais e mães que trabalhavam fora de casa, ao sexo da criança que levou o questionário para casa, ao tipo de coabitação da criança, à participação dos responsáveis no fornecimento dos diversos cuidados para a criança e às notas atribuídas por pais e mães às atitudes inadequadas das crianças. Utilizamos a análise de GLM para comparar as mães e os pais de uma mesma classe socioeconômica quanto às notas atribuídas às atitudes inadequadas das crianças. Os questionários respondidos por alunos bolsistas das escolas particulares não foram utilizados.

\section{Resultados}

\section{Sujeitos}

Dos 278 questionários analisados, 72 são de escolas particulares e 206 de escolas públicas. Categorizamos os respondentes em Mãe, Pai, Irmãos e Outros (avó, avô, tia, prima/primo, empregada, patroa - a mãe da criança era empregada doméstica, vizinha e avó de consideração - esta denominação foi utilizada pela própria respondente). A Mãe foi a principal respondente (69\%), considerando ambas as escolas. O Pai $(15,5 \%)$ e Outros $(13,5 \%)$ responderam menos freqüentemente e os Irmãos apareceram como respondentes apenas de crianças matriculadas nas escolas públicas (0,04\%). Não houve diferenças estatisticamente significativas entre as categorias de respondentes na comparação entre as escolas.

A escolaridade dos respondentes foi categorizada em: Cursou até o ensino médio e Cursou até a Pós-Gradução. Houve diferença significativa entre os respondentes das escolas particulares e públicas nas duas categorias (até o ensino médio, $\chi_{(\mathrm{gl}=1)}^{2}=62,7, p=0,0001$; até a Pós-Gradução, $\chi_{(\mathrm{gl}=1)}^{2}$ $=73,9, p=0,0001)$ sendo que o grau de escolaridade dos responsáveis pelas crianças de escolas públicas foi menor.

A maioria dos Pais respondentes trabalhava fora (particulares $=100 \%$, públicas $=91 \%$ ) enquanto cerca de $56 \%$ das Mães (particulares $=51 \%$, públicas $=61 \%$ ) o faziam. As diferenças entre Pais e entre Mães não foram estatisticamente significativas. Analisamos as respostas dos Pais e Mães respondentes, que declararam trabalhar, à questão: "Caso trabalhe fora, com quem fica a criança neste período?”. As crianças de escolas públicas ficaram significativamente mais com os parentes (pública $=41,48 \%$, particular $=21,43 \%$, $\left.\chi_{(\mathrm{gl}=1)}^{2}=5,54, p=0,01\right)$ enquanto as de escolas particulares ficaram mais com outras pessoas não aparentadas (públi$\mathrm{ca}=14,07 \%$, particular $\left.=47,62 \% ; \chi_{(\mathrm{gl}=1)}^{2}=20,98, p=0,0001\right)$. Os pais de crianças de escolas particulares e públicas não diferiram quanto à freqüência com a qual disseram que a criança ficava na escola (pública $=18,52 \%$, particular $=11,9 \%$ ), com o pai (pública $=4,76 \%$, particular $=8,15 \%$ ) e com a mãe (pública $=14,81 \%$, particular $=9,52 \%$ ) enquanto os pais trabalhavam.

Cento e quarenta e dois questionários foram respondidos por responsáveis por crianças do sexo masculino e cento e trinta e dois, por responsáveis por crianças do sexo feminino. Houve diferença estatisticamente significativa quando comparamos as escolas públicas e particulares em relação ao sexo das crianças $\left(\chi_{(\mathrm{gl}=1)}^{2}=8,87, p=0,003\right)$ sendo que houve maior representação de meninas na amostra obtida nas particulares (63\%) e mais meninos (56\%) na obtida nas escolas públicas.

\section{Coabitação}

A principal estrutura de coabitação das crianças de escolas públicas $(57,77 \%)$ e particulares $(48,61 \%)$ foi a família nuclear (coabitação com Pai, Mãe e Irmãos). A família extensa (Pai, Mãe, Irmãos e Outros) foi a segunda estrutura mais comum nas escolas particulares $(26,39 \%)$, diferindo significativamente das públicas $\left(13,59 \% ; \chi_{(\mathrm{gl}=1)}^{2}=6,2\right.$, $p=0,013)$ que apresentaram tanto as famílias extensas como as famílias monoparentais maternas extensas (Mãe, Irmãos e outros, públicas=15,05\%). As famílias monoparentais maternas extensas foi a terceira estrutura mais comum nas escolas particulares (16,67\%). A coabitação apenas com o Pai (monoparental paterna) ou com Outros e com Pai e outros (monoparental paterna extensiva) ocorreu raramente tanto nas escolas particulares $(1,39 \%$ e $0 \%$, respectivamente) como nas públicas (2,43\% e 0,49\%, respectivamente).

$\mathrm{Na}$ categoria Outros apenas a coabitação de crianças com os tios diferiu significativamente $\left(\chi_{(\mathrm{gl}=1)}^{2}=4,24, p=0,04\right)$ entre as escolas particulares $(4,17 \%)$ e públicas $(11,58 \%)$. Outros apontados na coabitação com as crianças foram, em média: avô $(6,81 \%)$ e avó (14,93\%) maternos, avô $(2,88 \%)$ e avó $(5,23 \%)$ paternos, tia $(10,58 \%)$, primos $(4,46 \%)$, bisavós $(1,57 \%)$, padrastos (0,79\%), empregados $(8,36 \%)$ e patroa $(1,57 \%)$. O número de pessoas com as quais crianças de ambas as escolas coabitaram diferiu significativamente $\left(\chi_{(\mathrm{gl}=1)}^{2}=3,96, p=0,046\right)$ sendo que houve mais coabitantes com as crianças de escolas particulares $(1,33)$ que com as de escolas públicas $(0,99)$.

\section{Cuidados com a Criança}

$\mathrm{Na}$ tarefa de levar a criança à escola encontramos apenas uma diferença significativa na participação das categorias de cuidadores (Tabela 1): o Pai de crianças de escolas públicas apareceu como responsável exclusivo por esta tarefa significativamente mais $\left(\chi_{(\mathrm{gl}=1)}^{2}=4,9, p=0,03\right)$ que o de crianças de escolas particulares. No entanto, enquanto o responsável apontado mais freqüentemente nas escolas particulares foi a Mãe, nas escolas públicas a Mãe e Pai e mãe juntos, foram apontados com a mesma freqüência. Ainda, enquanto os Pais e mães juntos de crianças de escolas par- 
ticulares receberam mais auxílio de outros para levá-las à escola, as Mães de crianças de escolas públicas receberam mais auxílio de outros que as Mães de escolas particulares. Outras pessoas, além dos pais, que desempenharam esta tarefa como cuidadores exclusivos (ou seja, foram apontados como únicos responsáveis pelo cuidado) corresponderam a cerca de $8 \%$ em ambas as escolas (Tabela 1).

Várias pessoas participaram desta tarefa como cuidadores exclusivos ou co-responsáveis (ou seja, foram apontados como participando dos cuidados juntamente com um ou ambos os pais ou outros alocuidadores, Tabela 2). As irmãs $\left(\chi_{(\mathrm{gl}=1)}^{2}=8,95, p=0,003\right)$, os irmãos, avós, tias e primos foram apontados como alocuidadores mais freqüentemente pelos responsáveis por crianças de escolas públicas, enquanto empregada $\left(\chi_{(\mathrm{gl}=1)}^{2}=10,03, p=0,001\right)$, motorista $\left(\chi_{(\mathrm{gl}=1)}^{2}=4,61, p=0,03\right)$ e transporte escolar foram mais freqüentemente apontados como responsáveis por crianças de escolas particulares. Avôs e tios foram apontados em ambas as escolas com pequena freqüência, enquanto padrasto, vizinho e cunhado foram apontados apenas nas escolas públicas.

Nas escolas particulares os principais responsáveis pelos gastos com a criança foram os Pais $\left(\chi_{(\mathrm{gl}=1)}^{2}=8,04\right.$, $p=0.005)$ enquanto nas públicas foram os Pais e mães em conjunto $\left(\chi_{(\mathrm{gl}=1)}^{2}=4,15, p=0.04\right)$ e os Pais sozinhos (Tabela 1). Pais e mães em conjunto apareceram em seguida nas escolas particulares enquanto Mães sozinhas aparecem nas públicas. Outras pessoas, como responsáveis exclusivos, apareceram mais freqüentemente nas particulares. Mãe e outros e Pai e outros apareceram menos freqüentemente tanto nas escolas públicas quanto nas particulares e Pai, Mãe e outros foram apontados como responsáveis apenas nas públicas.

As avós foram as principais alocuidadoras apontadas como responsáveis pelos gastos com as crianças em ambas as escolas. Os avôs foram os segundos e as tias as tercei- ras. Padrastos, tios e padrinhos foram apontados como alocuidadores apenas nas escolas públicas (Tabela 2).

A Mãe foi a principal responsável por cuidar da alimentação da criança em ambas as escolas (Tabela 1). A categoria Mãe e outros apareceu em seguida. Nas escolas particulares as categorias Outros $\left(\chi_{(\mathrm{gl}=1)}^{2}=6,13, p=0.013\right)$ e Pai, mãe e outros apareceram mais freqüentemente que nas públicas. Nas escolas públicas a categoria Pai e mãe ocorreu significativamente mais que nas particulares $\left(\chi_{(\mathrm{gl}=1)}^{2}=7,27, p=0.007\right)$.

A avó foi a principal alocuidadora responsável por esta tarefa em ambas as escolas (Tabela 2). A empregada se mostrou a segunda principal responsável e foi apontada significativamente mais nas escolas particulares que nas públicas $\left(\chi_{(\mathrm{gl}=1)}^{2}=10,1, p=0.0015\right)$. As tias e o avô foram apontados como responsáveis pela alimentação das crianças de escolas particulares e públicas e a $\operatorname{irmã~}\left(\chi_{(\mathrm{gl}=1)}^{2}=3,98\right.$, $p=0.0461)$, a escola, o irmão, o tio, a bisavó e o primo(a) foram apontados exclusivamente nas públicas (Tabela 2).

A Mãe foi a principal responsável por cuidar da higiene da criança em ambas as escolas (Tabela 1). Enquanto nas escolas particulares a categoria Mãe e outros foi a segunda mais apontada, nas públicas as categorias Mãe e outros e Pai e mãe ocuparam esta posição. As categorias Pai, Pai, mãe e outros e Outros $\left(\chi_{(\mathrm{gl}=1)}^{2}=5,8, p=0.0158\right)$ predominaram nas escolas particulares enquanto Pai e outros ocorreu apenas nas públicas.

A empregada foi apontada mais freqüentemente nas escolas particulares como responsável pela higiene das crianças $\left(\chi_{(\mathrm{gl}=1)}^{2}=16,83, p=0.0001\right)$, diferentemente das públicas, nas quais a avó foi a principal responsável (Tabela 2). Nas escolas particulares a avó apareceu como segunda principal responsável. Outros cuidadores aparentados, a irmã $\left(\chi_{(\mathrm{gl}=1)}^{2}=4,3, p=0.037\right)$ e a tia, foram apontados com maior freqüência nas escolas públicas. O padrasto, o avô, o tio, o primo(a) e a escola for am apontados como responsáveis pela higiene apenas nas escolas públicas.

Tabela 1

Freqüência com que cada Classe de Cuidador foi apontada como Responsável, em Escolas Públicas e Particulares, por: levar as Crianças a Escola, Gastos com a Criança, Alimentação e Higiene da Criança

\begin{tabular}{|c|c|c|c|c|c|c|c|c|}
\hline \multirow[b]{3}{*}{ Categorias de cuidadores } & \multicolumn{8}{|c|}{ Cuidados } \\
\hline & \multicolumn{2}{|c|}{ Levar a escola } & \multicolumn{2}{|c|}{ Gastos } & \multicolumn{2}{|c|}{ Alimentação } & \multicolumn{2}{|c|}{ Higiene } \\
\hline & Particular & Pública & Particular & Pública & Particular & Pública & Particular & Pública \\
\hline Pai & $1,39 \%$ & $9,22 \%$ & $45,83 \%$ & $27,67 \%$ & $1,39 \%$ & $1,46 \%$ & $1,39 \%$ & $0,00 \%$ \\
\hline Mãe & $26,39 \%$ & $24,76 \%$ & $9,72 \%$ & $17,96 \%$ & $41,67 \%$ & $47,09 \%$ & $44,44 \%$ & $50,00 \%$ \\
\hline Pai e mãe & $18,06 \%$ & $25,73 \%$ & $26,39 \%$ & $39,81 \%$ & $2,78 \%$ & $14,56 \%$ & $8,33 \%$ & $16,50 \%$ \\
\hline Pai, mãe e outros & $13,89 \%$ & $7,77 \%$ & $0,00 \%$ & $0,97 \%$ & $15,28 \%$ & $7,77 \%$ & $12,50 \%$ & $5,83 \%$ \\
\hline Pai e outros & $2,78 \%$ & $2,43 \%$ & $1,39 \%$ & $1,94 \%$ & $0,00 \%$ & $1,46 \%$ & $0,00 \%$ & $0,97 \%$ \\
\hline Mãe e outros & $9,72 \%$ & $16,50 \%$ & $5,56 \%$ & $6,80 \%$ & $20,83 \%$ & $17,48 \%$ & $19,44 \%$ & $17,48 \%$ \\
\hline Outros & $8,33 \%$ & $8,25 \%$ & $9,72 \%$ & $3,88 \%$ & $16,67 \%$ & $6,80 \%$ & $12,50 \%$ & $4,37 \%$ \\
\hline Não respondeu & $1,39 \%$ & $0,49 \%$ & $1,39 \%$ & $0,97 \%$ & $1,39 \%$ & $3,40 \%$ & $1,39 \%$ & $4,85 \%$ \\
\hline
\end{tabular}

Nota. O realce em negrito indica diferenças significativas $(\alpha<0,05)$ entre os cuidadores das crianças matriculadas nas escolas públicas e particulares 
Silva, L. W. \& Tokumaru, R. (2008). Cuidados Parentais e Aloparentais Recebidos por Crianças de Escolas Públicas

e Particulares de Vitória - ES.

Tabela 2

Freqüência com que cada Pessoa (exceto Pais) foi apontada, em Escolas Públicas e Particulares, por: levar as Crianças a Escola, Gastos com a Criança, Alimentação e Higiene da Criança

\begin{tabular}{|c|c|c|c|c|c|c|c|c|}
\hline \multirow[b]{3}{*}{ Cuidadores } & \multicolumn{6}{|c|}{ Cuidados } & & \\
\hline & \multicolumn{2}{|c|}{ Levar a escola } & \multicolumn{2}{|l|}{ Gastos } & \multicolumn{2}{|c|}{ Alimentação } & \multicolumn{2}{|l|}{ Higiene } \\
\hline & Particular & Pública & Particular & Pública & Particular & Pública & Particular & Pública \\
\hline Irmã & $0,00 \%$ & $16,82 \%$ & $0,00 \%$ & $0,00 \%$ & $0,00 \%$ & $8,54 \%$ & $0,00 \%$ & $12,12 \%$ \\
\hline Irmão & $2,13 \%$ & $9,35 \%$ & O,OO\% & $0,00 \%$ & 0,00\% & $3,66 \%$ & $3,03 \%$ & $1,52 \%$ \\
\hline Padrasto & $\mathrm{O}, \mathrm{OO} \%$ & $0,93 \%$ & $0,00 \%$ & $2,70 \%$ & $0,00 \%$ & $\mathrm{O}, \mathrm{OO} \%$ & $\mathrm{O}, \mathrm{OO} \%$ & $1,52 \%$ \\
\hline Avó & $19,15 \%$ & $20,56 \%$ & $57,14 \%$ & $45,95 \%$ & $45,45 \%$ & $39,02 \%$ & $33,33 \%$ & $39,39 \%$ \\
\hline Avô & $8,51 \%$ & $5,61 \%$ & $21,43 \%$ & $24,32 \%$ & $4,55 \%$ & $6,10 \%$ & 0,00\% & $6,06 \%$ \\
\hline Tio & $4,26 \%$ & $4,67 \%$ & $0,00 \%$ & $2,70 \%$ & $0,00 \%$ & $2,44 \%$ & $0,00 \%$ & $1,52 \%$ \\
\hline Tia & $10,64 \%$ & $19,63 \%$ & $7,14 \%$ & $16,22 \%$ & $6,82 \%$ & $14,63 \%$ & $9,09 \%$ & $19,70 \%$ \\
\hline Bisavó & $0,00 \%$ & $0,00 \%$ & 0,00\% & $0,00 \%$ & $0,00 \%$ & $1,22 \%$ & 0,00\% & $0,00 \%$ \\
\hline Primo(a) & $2,13 \%$ & $4,67 \%$ & $0,00 \%$ & $0,00 \%$ & 0,00\% & $1,22 \%$ & 0,00\% & $1,52 \%$ \\
\hline Vizinho(a) & 0,O०\% & $0,93 \%$ & $0,00 \%$ & $0,00 \%$ & $0,00 \%$ & $0,00 \%$ & $0,00 \%$ & $0,00 \%$ \\
\hline Cunhado(a) & $0,00 \%$ & 0,93\% & $0,00 \%$ & $0,00 \%$ & $0,00 \%$ & $0,00 \%$ & 0,00\% & $0,00 \%$ \\
\hline Empregada & $19,15 \%$ & $\mathbf{3 , 7 4} \%$ & $0,00 \%$ & $\mathrm{O}, \mathrm{OO} \%$ & $43,18 \%$ & $17,07 \%$ & $54,55 \%$ & $15,15 \%$ \\
\hline Transporte Escolar & $29,79 \%$ & $12,15 \%$ & $\mathrm{O}, \mathrm{OO} \%$ & $\mathrm{O}, \mathrm{OO} \%$ & $\mathrm{O}, \mathrm{OO} \%$ & $\mathrm{O}, \mathrm{OO} \%$ & $\mathrm{O}, \mathrm{OO} \%$ & $\mathrm{O}, \mathrm{OO} \%$ \\
\hline Motorista & $4,26 \%$ & $0,00 \%$ & $0,00 \%$ & $0,00 \%$ & $0,00 \%$ & $0,00 \%$ & $0,00 \%$ & $0,00 \%$ \\
\hline Padrinho & $0,00 \%$ & $0,00 \%$ & $0,00 \%$ & $2,70 \%$ & $0,00 \%$ & $0,00 \%$ & 0,00\% & $0,00 \%$ \\
\hline Escola & O,OO\% & O,OO\% & O,OO\% & O,OO\% & O,OO\% & $6,10 \%$ & O,OO\% & $1,52 \%$ \\
\hline
\end{tabular}

Nota. O realce em negrito indica diferenças significativas $(\alpha<0,05)$ entre os cuidadores das crianças matriculadas nas escolas públicas e particulares.

Para a análise da freqüência com que os respondentes disseram realizar as diversas atividades com seus filhos consideramos apenas os Pais e Mães respondentes dado o baixo número de outros respondentes nas escolas particulares.

Mães e Pais (Figura 1) de crianças de escolas públicas diferiram pouco dos de escolas particulares na freqüência com que realizaram as diversas atividades com seus filhos. As Mães de crianças da escola particular auxiliaram mais seus filhos nas tarefas escolares $(Z=-2,08, p=0,04)$ enquanto as de escolas públicas cuidaram mais da alimentação $(Z=-4,29, p=0,002)$ e da higiene $(Z=-4,25, p=0,003)$. A única diferença significativa entre os Pais foi na freqüência com que disseram levar seus filhos à escola sendo que os de crianças de escola pública realizaram esta tarefa mais freqüentemente que os de escolas particulares $(Z=-$ 2,53, $p=0,01)$. 

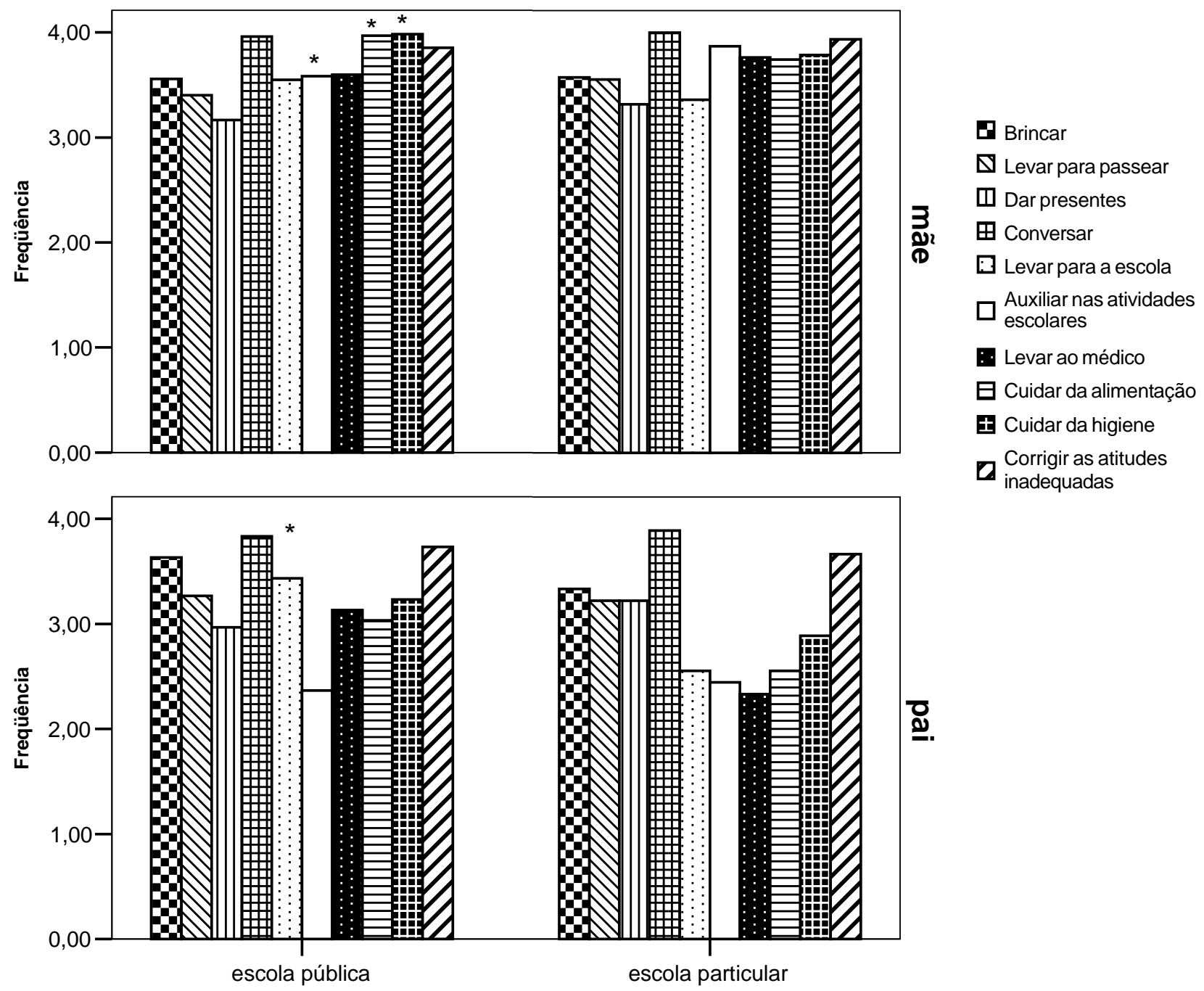

Figura 1. Frequiência: (1 - não realiza, 2 - realiza poucas vezes, 3 - realiza às vezes, 4 - realiza muitas vezes) com que pais e mães de crianças matriculadas em escolas públicas e particulares declararam realizar cada atividade com seus filhos. Os asteriscos indicam diferenças significativas $(\alpha<0,05)$ entre os cuidadores das crianças matriculadas nas escolas públicas e particulares.

Observamos que as Mães de crianças de ambas as escolas não apresentaram diferenças significativas quanto ao julgamento da gravidade das atitudes inadequadas das crianças (Figura 2). No entanto, tanto as Mães de crianças da escola pública quanto da particular consideraram atitudes como falta de respeito e brincadeiras perigosas como sendo mais graves que teimosia e gritos. A gravidade atribuída pelas Mães (média igual a 2,84) às diversas atitudes inadequadas foi relativamente menor que a atribuída pelos Pais (média igual a 3,13). Os Pais de crianças da escola particular (média igual a 3,59) atribuíram, em média, maior gravidade às atitudes inadequadas que os de crianças de escola pública (média igual a 2,94). No entanto, apenas duas diferenças foram estatisticamente significativas, o julgamento de desobediência e de gritos (Figura 2). Os Pais também atribuíram graus de gravidade diferentes às diferentes atitudes.

Os pais e as mães de crianças matriculadas nas escolas públicas foram mais semelhantes entre si no julgamento da gravidade das atitudes inadequadas das crianças (GLM, $\mathrm{F}=1,35, p=0,2)$ que os pais de crianças matriculadas nas escolas particulares (GLM, $\mathrm{F}=2,14, p=0,03$ ). 
Silva, L. W. \& Tokumaru, R. (2008). Cuidados Parentais e Aloparentais Recebidos por Crianças de Escolas Públicas e Particulares de Vitória - ES.
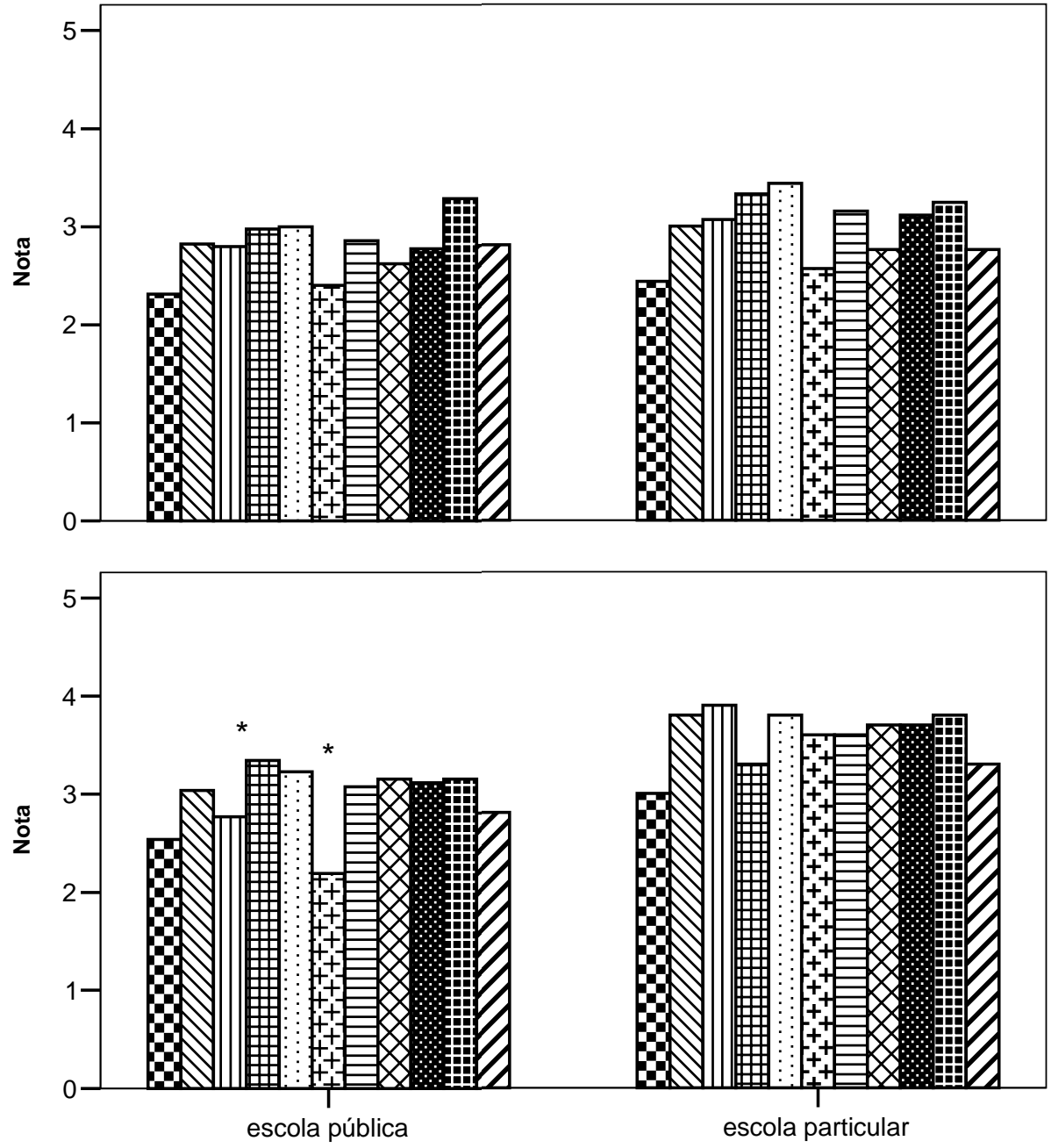

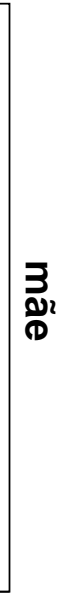

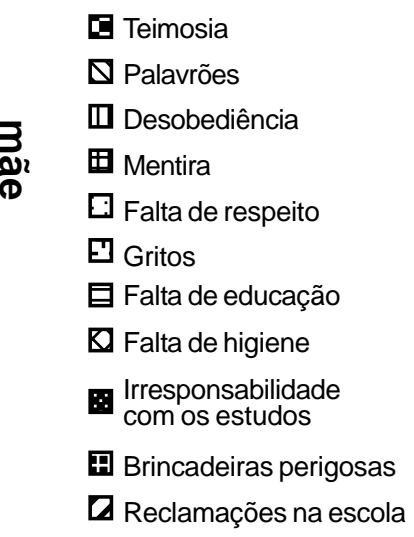

Figura 2. (1-nada grave, 2-pouco grave, 3-grave, 4-muito grave, 5-extremamente grave) atribuída por pais e mães de crianças matriculadas em escolas públicas e particulares à atitudes inadequadas das crianças.

\section{Discussão}

Confirmamos a partir de nossos resultados que há diferenças entre os pais e os alocuidadores (Hrdy, 2006). Os pais se apresentaram como os maiores responsáveis pelos cuidados fornecidos às crianças. No entanto, os alocuidadores participaram de todos os cuidados mensurados como co-responsáveis e como responsáveis exclusivos em algumas tarefas.

Estes dados vão ao encontro das idéias de A. M. A. Carvalho (1998) sobre um padrão geral na prática de criação de filhos, propondo que as relações das crianças com outros adultos se estenda ao longo de todo o seu desenvolvimento. A constatação da participação extensiva dos alocuidadores vai ao encontro também da Hipótese da Reprodução Cooperativa de Hrdy (2006) que considera que a ajuda aloparental foi essencial para a sobrevivência das crianças e que este traço teria sido selecionado ao longo da evolução humana. A teoria se utiliza da regra de Hamilton para explicar o altruísmo dos alocuidadores, ou seja, o custo do fornecimento do cuidado deve ser menor que o benefício obtido pela prole, calibrados em relação ao grau de parentesco entre os alocuidadores e a prole. Nossos dados em relação à participação dos avós apontam para a impor tância do parentesco entre alocuidador e criança. As avós foram as principais responsáveis, além das mães e dos pais, em todos os cuidados mensurados.

A diferença estatisticamente significativa no grau de escolaridade encontrada entre os cuidadores das crianças matriculadas nas escolas públicas e particulares da nossa amostra indica diferenças socioeconômicas. Outras diferenças não significativas como a preponderância de coabitação com empregados nas famílias de crianças de escolas particulares e com parentes nas famílias de crianças de escolas públicas, preponderância de famílias monoparentais extensivas maternas na amostra de crianças de escolas públicas e coabitação com um número maior de irmãos podem indicar que as crianças matriculadas em escolas particulares têm realmente maior poder aquisitivo. Estas diferenças foram associadas a maior responsabilidade das empregadas de crianças matriculadas nas escolas particulares e das irmãs das crianças de escolas públicas nas tare- 
fas de alimentação, higiene e levar as crianças à escola. Parece-nos, portanto, que houve influência da classe socioeconômica sobre a participação dos alocuidadores sendo que na classe mais baixa houve maior participação de parentes enquanto na classe mais alta houve maior participação de empregados.

Apesar da maior coabitação com parentes e maior cuidado fornecido por estes, observamos que para as crianças matriculadas nas escolas públicas, houve atribuição de responsabilidade à escola no fornecimento de cuidados como alimentação e higiene. Parece-nos, que a escola tem, para estas crianças, um papel no fornecimento de cuidados, além do papel na educação formal.

Os pais e mães de crianças de escolas públicas compartilharam mais a responsabilidade pelos gastos e alimentação da criança que os de escola particular. Pais e mães de crianças de escolas públicas também foram mais semelhantes ao julgar a gravidade das atitudes inadequadas de seus filhos. Estas diferenças parecem indicar que houve maior compartilhamento entre pai e mãe no fornecimento de cuidados às crianças matriculadas em escolas públicas que às matriculadas em escolas particulares.

As mães de crianças de escolas públicas foram mais apontadas como responsáveis pela alimentação e higiene de seus filhos enquanto as de crianças de escolas particulares foram mais apontadas como responsáveis pela supervisão das tarefas escolares. Isto pode refletir o auxílio que mães de crianças de escolas particulares têm de empregadas que participam dos cuidados de alimentação e higiene, mas não da supervisão de tarefas escolares, enquanto as mães de crianças de escola pública, que têm menor escolaridade e contam menos com auxílio de empregados, se concentram nos cuidados básicos.

As principais diferenças entre os cuidados fornecidos pelos pais e mães de crianças de escolas públicas e particulares relacionam-se, como dito anteriormente, às condições econômicas destas famílias que parecem levar a um maior compartilhamento das tarefas entre os pais e mães de escolas públicas. No entanto, as semelhanças entre as mães e entre os pais dos diferentes contextos podem indicar a manutenção de papéis socialmente definidos. Em nossa amostra, a maioria dos questionários foi respondida pelas mães, talvez porque estejam menos envolvidas com atividades extra-lar, trabalhando fora de casa menos freqüentemente que os pais, ou porque a responsabilidade pela supervisão das tarefas escolares dos filhos tenha sido tradicionalmente atribuída às mães (Trindade, 1998; Wagner et al., 2005). Também disseram participar mais dos cuidados relacionados à alimentação, higiene, educação e saúde da criança, além de conversar freqüentemente com ela. Os cuidados nos quais disseram participar menos são os relacionados ao lazer e ao transporte para a escola.

A manutenção dos papéis de gênero tradicionais transpareceu também no tipo de responsabilidade atribuída aos alocuidadores. Em cuidados como alimentação e higiene da criança a mãe foi a principal cuidadora e a avó, a segun- da principal. Além disso, as irmãs mais que irmãos e as tias mais que tios foram apontadas mais freqüentemente mostrando que as mulheres têm maior responsabilidade pelos cuidados básicos com as crianças. As mães também apresentaram maior tolerância com as atitudes inadequadas das crianças, julgando-as como menos graves.

Os pais foram os segundos principais respondentes, porém diferiram pouco da categoria Outros, mostrando pequena participação como responsáveis pela supervisão das tarefas escolares da criança. Os pais que responderam o questionário disseram participar mais freqüentemente dos cuidados relacionados à correção das atitudes inadequadas da criança, à conversa e ao lazer (brincar, dar presentes, passear). Estiveram menos freqüentemente presentes nos cuidados básicos (alimentação e higiene) e nos relacionados à supervisão escolar e à saúde (levar ao médico).

Os irmãos foram freqüentemente apontados como coresponsáveis pelos cuidados com as crianças, principalmente pelas crianças de escolas públicas. Outros autores ressaltaram a importância financeira que a presença de vários filhos têm para famílias de baixa renda (Amazonas et al., 2003) e as conseqüências do cuidar para os irmãos que cuidam e para os que são cuidados (Ferreira \& Mettel, 1999) sugerindo que pode haver conseqüências positivas e negativas para ambos. Em outras espécies, jovens maduros sexualmente, mas não acasalados, podem cuidar dos irmãos mais novos, e mostram maior sucesso reprodutivo quando adultos que outros que não tiveram experiência prévia (Yamamoto \& Souza, 1998).

Em conclusão, vimos que houve presença de alocuidadores em todos os cuidados mensurados, demonstrando uma possível dependência dos pais da presença de alocuidadores para a manutenção de seus filhos. A participação dos alocuidadores nos vários cuidados pareceu variar. Houve, por exemplo, a participação de maior variedade de alocuidadores na tarefa de levar a criança à escola que como responsáveis pelos gastos. Isto pode indicar diferença nos custos destes cuidados.

Nosso objetivo neste trabalho foi investigar diferenças na participação dos alocuidadores em dois contextos sócio-econômicos. Mostramos que há diferenças. Restam questões quanto as possíveis influências destas diferenças no desenvolvimento das crianças.

\section{Referências}

Amazonas, M. C. L. A., Damasceno, P. R., Terto, L. M. S., \& Silva, R. R. (2003). Arranjos familiares de crianças das camadas populares [Edição especial]. Psicologia em Estudo, 8, 1120.

Braz, M. P., Dessen, M. A., \& Silva, N. L. P. (2005). Relações conjugais e parentais: Uma comparação entre famílias de classes sociais baixa e média. Psicologia: Reflexão e Crítica, 18(2), 151-161.

Bussab, V. S. R., \& Ribeiro, F. L. (1998). Biologicamente cultural. In L. Souza, M. F. Q. Freitas \& M. M. P. Rodrigues (Eds.), Psicologia: Reflexões (im)pertinentes (pp. 175-193). São Paulo, SP: Casa do Psicólogo. 
Carvalho, A. M. A. (1998). Etologia e comportamento social. In L. Souza, M. F. Q. de Freitas \& M. M. P. Rodrigues (Eds.), Psicologia: Reflexões (im)pertinentes (pp. 195-224). São Paulo, SP: Casa do Psicólogo.

Carvalho, I. M. M., \& Almeida, P. H. (2003). Família e proteção social. São Paulo em Perspectiva, 17(2), 109-122.

Ferreira, E. A. P., \& Mettel, T. P. L. (1999). Interação entre irmãos em situação de cuidados formais. Psicologia: Reflexão $e$ Crítica, 12(1), 133-146.

Geary, D. C., \& Flinn, M. V. (2001). Evolution of human parental behavior and the human family. Parenting: Science and Practice, $1,5-61$.

Hrdy, S. B. (2001). Mãe natureza - Uma visão feminina da evolução: Maternidade e seleção natural. Rio de Janeiro, RJ: Campos.

Hrdy, S. B. (2006). Evolutionary context of human development: The cooperative breeding model. In C. S. Carter \& L. Ahnert (Eds.), Attachment and bonding: A new synthesis. Cambridge, MA: M.I.T. Press.

Instituto Brasileiro de Geografia e Estatística. (2006). Censo. Brasília, DF: Autor. Retirado de http://www.ibge.gov.br Instituto Nacional de Estudos e Pesquisas Educacionais. (2006). Censo. Brasília, DF: Autor. Retirado de http://www.inep.gov.br

Key, C. A., \& Aiello, L. C. (1999). The evolution of social organization. In R. I. N. Dunbar, C. Knight \& K. C. Power (Eds.), The evolution of culture (pp. 15-33). Chapel Hill, NC: Rutgers University Press.

La Rosa, J. (1998). Ansiedade, sexo, nível sócio-econômico e ordem de nascimento. Psicologia: Reflexão e Crítica 11(1), 59-70.

Leão, L. S. C. de S., Araújo, L. M. B., Moraes, L. T. L. P. \& Assis, A. M. (2003). Prevalência de obesidade em escolares de Salvador, Bahia. Arquivos Brasileiros de Endocrinologia छ Metabologia, 47(2), 151-157.

Lordelo, E. R., Fonseca, A. L., \& Araújo, M. L. V. B. (2000). Responsividade do ambiente de desenvolvimento: Crenças e práticas como sistema cultural de criação de filhos. Psicologia: Reflexão e Crítica, 13(1), 2-16.

Machado, R. C., Marcari, E. L., Cristante, S. F. V., \& Carareto, C. M. A. (1999). Giardíase e helmintíases em crianças de creches e escolas de $1^{\circ}$ e $2^{\circ}$ graus (públicas e privadas) da cidade de Mirassol (SP, Brasil). Revista da Sociedade Brasileira de Medicina Tropical, 32, 697-704

Martins, L. B. M., Costa-Paiva, L. H. S., Osis, M. J., Sousa, M. H., Pinto-Neto, A. M., \& Tadini, V. (2006). Fatores associados ao uso de preservativo masculino e ao conhecimento sobre DST/AIDS em adolescentes de escolas públicas e privadas do município de São Paulo, Brasil. Cadernos de Saúde Pública, 22(2), 315-323.

Oliveira E. A., Frizzo, G. B., \& Marin, A. H. (2000). Atitudes maternas diferenciais para com meninos e meninas de quatro e cinco anos. Psicologia Reflexão e Crítica, 13(3), 363-371.

Österberg, V. (2000). Childreen's living conditions in Sweden. Social patterns and trends in parental accessibility, child care and economic resources. International Journal of Social Welfare, 9, 64-75.

Pinho, A. G. (2001). Reflexões sobre o papel do concurso vestibular para as universidades públicas. Estudos Avançados, 15(42), 353-362.

Pires, M. C., \& Lopes, A. S. (2004). Crescimento físico e características sócio-demográficas em escolares no município de Florianópolis - SC, Brasil. Revista Brasileira de Cineantropometria e Desempenho Humano, 6(2), 17-26.

Rapoport, A., \& Piccinini, C. A. (2004). A escolha do cuidado alternativo para o bebê e a criança pequena. Estudos de Psicologia, 9(3), 497-503.
Rodrigues, M. M. P. (1998). Evolução do investimento parental em primatas. O caso do Homo sapiens. In L. Souza, M. F. Q. de Freitas \& M. M. P. Rodrigues (Eds.), Psicologia: Reflexões (im)pertinentes (pp. 273-292). São Paulo, SP: Casa do Psicólogo.

Roulin, A. (2002). Why do lactating females nurse alien offspring? A review of hypotheses and empirical evidence. Animal Behaviour, 63, 201-208.

Silva, S. S. C., Pendu, Y., \& Pontes, F. A. R. (2002). Sensibilidade materna durante o banho. Psicologia: Teoria e Pesquisa 18(3), 345-352.

Trindade, Z. A. (1998). Concepções de maternidade e paternidade: O convívio atual com fantasmas do século XVIII. In L. Souza, M. F. Q. Freitas \& M. M. P. Rodrigues (Eds.), Psicologia: Reflexões (im)pertinentes (pp. 129-155). São Paulo, SP: Casa do Psicólogo.

Wagner, A., Predebon, J. C., Mosmann, C., \& Verza, F. (2005). Compartilhar tarefas? Papéis e funções de pai e mãe na família contemporânea. Psicologia: Teoria e Pesquisa, 21, 181-186.

Yamamoto, M. E., \& Souza, M. B. C. (1998). Sistema social dos calitriquídeos: Dados atuais e novas perspectivas de investigação. In L. Souza, M. F. Q. Freitas \& M. M. P. Rodrigues (Eds.), Psicologia: Reflexões (im)pertinentes (pp. 247-272). São Paulo, SP: Casa do Psicólogo. 